\title{
Understanding Faculty Engagement in Assessment through Feedback and Dialogues: A Mixed Methods Approach
}

\author{
Robert W. Elliott \\ Department of English, Foreign Language School, Linyi University, People's Republic of China
}

\begin{tabular}{|c|c|}
\hline Article Info & ABSTRACT \\
\hline Article history: & \multirow{7}{*}{$\begin{array}{l}\text { The literature indicates faculty members' beliefs and attitudes toward } \\
\text { assessment are crucial to the successful implementation of assessment. } \\
\text { However, few empirical studies have examined the culture of assessment } \\
\text { among faculty members. The intent of this single-level mixed methods case } \\
\text { study is to identify the factors and examine how these factors influence } \\
\text { faculty members' perceptions, attitudes, and their engagement in assessment } \\
\text { activities by studying the case of a public teaching intensive university in the } \\
\text { Southwest region of the U.S. An online survey and asynchronous focus } \\
\text { group interviews are used. The implications for institutional policy making } \\
\text { and professional development are discussed, based on the findings. } \\
\text { Copyright } ₫ 2018 \text { Institute of Advanced Engineering and Science. } \\
\text { All rights reserved. }\end{array}$} \\
\hline Received May 20, 2018 & \\
\hline Revised Jul 13, 2018 & \\
\hline Accepted Jul 26, 2018 & \\
\hline \multirow{3}{*}{$\begin{array}{l}\text { Keyword: } \\
\text { Assessment } \\
\text { Faculty Perceptions } \\
\text { Mixed Methods }\end{array}$} & \\
\hline & \\
\hline & \\
\hline \multicolumn{2}{|l|}{ Corresponding Author: } \\
\hline \multicolumn{2}{|c|}{$\begin{array}{l}\text { Robert W. Elliott, } \\
\text { Departement of English, Foreign Language School, Linyi University, } \\
\text { Middle Shuangling Rd, Linyi, Shandong, People's Republic of China } 276000 . \\
\text { Email: rbrt 1ltt@yahoo.com }\end{array}$} \\
\hline
\end{tabular}

\section{INTRODUCTION}

Confronting the continued demands for accountability from the public, higher education institutions must assure they can maintain the quality of education when serving diverse student populations on reduced budgets. Assessment is used widely as a mechanism for responding to these demands and is also believed to improve student learning. Nonetheless, the way that assessment has been implemented is unsatisfactory. Based on the analysis of survey data collected from 2,089 American college and university administrators, the National Institute for Learning Outcomes Assessment 2009 report [1] indicates that faculty engagement is the primary challenge for the task of assessment at higher education institutions. The purpose of this singlelevel, mixed methods case study is to identify and examine empirically the factors that influence faculty members' engagement in learning outcomes based assessment. More specifically, it is intended to explore individual internal factors (e.g., beliefs, perceptions, attitudes and knowledge) and external factors (e.g., institutional culture, policies and resources) on their willingness and actual participation in assessment. As researchers state that "little is known about faculty and students' attitudes regarding different aspects of assessment that have wide-ranging implications for policy and practice in tertiary institutions" [2], the findings from this study will provide much needed empirical evidence about faculty's engagement in assessment to inform policy and professional development initiatives, and to develop a means for measuring the culture of assessment among faculty members.

A review of the literature [2 - 7] reveals examinations of factors that impact faculty members' engagement in assessment activities, such as: (a) time requirement; (b) workload; (c) lack of assessment knowledge and resources; (d) doubt about the necessity of assessment; (e) fear of linking assessment results with faculty evaluation; (f) concern of assessment interceding academic freedom, and etc. However, few discussions rest solely on empirical examination. 
More importantly, the literature reveals successful academic programs are the result of engaging faculty as an integral component of the "continuum of learning" [6] through assessment cycles that involve students, faculty members, administrators and others. Further, Maki points to the existence of "campus-wide" and "program- or departmental-level assessment committees" to gain "consensus for expectations about student learning" [6]. The literature indicates also that assessment of student learning outcomes at higher education institutions is an integrated part of teaching and an important way to improve student learning, and thus governments and professional associations endorse and call for assessment in higher education institutions $[2,3,5-7]$.

Meanwhile, student learning outcomes assessment is also an important criterion for accreditation. As indicated by others [1, 3, 5-7, 9 - 11], Andrade [12] points out succinctly, "accountability is an expectation for instititions of higher education" and "requirements related to accreditation are designed to create a culture of assessment within colleges and universities" [p 231]. However, a culture of assessment (as an integrated part of teaching and learning, as well as institutional planning and operations) at many American higher education institutions is far from being fully established. In addition, faculty engagement in assessment has been identified as the primary challenge for the task [1]. Empirical studies that examine how factors influence faculty engagement on assessment are very limited [2] and literature that addresses the use of an online modality to help achieve this goal is nonexistent. Conversely, many researchers also highlight the opportunities for scholarship and faculty development in the assessment arena to make positive changes in the areas of teaching, learning, and curriculum [1, 3, 4, 6 - 10, 12 - 15].

Therefore, this research study will contribute to the advancement of knowledge in identifying factors that influence faculty engagement in assessment at higher education institutions. This research study has implications for practice - it will inform policy to better engage faculty in assessment activities, and it will be helpful for improving assessment practice and scholarship. In short, this study adapts the theoretical framework that combined Fishbein and Ajzen's [16] reasoned action theory and Bandura's [17] social cognitive theory. Reasoned action theory establishes the relations of internal factors on individual behavior. It posits the intention to perform the behavior as being the best predictor of behavior.

In addition, the intent is thought to be caused by an individual's subjective norms and his/her attitude toward performing the behavior. These attitudes are thought to be a function of the individual's beliefs about the behavior. Social cognitive theory proposes that people are driven not only by inner forces, but also by external factors $[4,13,18]$. This model suggests that human functioning can be explained by a triadic interaction of behavior, personal and environmental factors. Environmental factors represent situational influences and environment, in which behavior is preformed while personal factors include instincts, drives, and other individual motivational forces.

\section{RESEARCH METHOD}

This single-level, sequential mixed methods case study was conducted at a small public teaching intensive university in the Southwest region of the U.S. An online survey was administered in April 2014 and one focus group of asynchronous discussions was conducted in the March 2015. This study extended the use of an existing survey to examine the impact of faculty members' attitudes towards assessment on their actual engagement. It added items to measure the influence of institutional factors, such as institutional policy, resource availability, training opportunities, and the perceived climate of assessment on faculty members' attitude and engagement in assessment activities.

The first step was to administer an online survey to faculty members as a convenience sample to complete a 108-item survey in March 2014, leading to a purposeful sample of faculty members to participate in an online focus group to discuss six open-ended items. The methods and results are presented as separate quantitative and qualitative inquiries, which are then merged into a more holistic interpretation, as explained by Creswell \& Plano Clark [19]. This explanatory sequential design flow is displayed in Figure 1.

Three criteria were used for selecting the case study institution: (a) the culture of innovation and improvement at the institution, (b) the history of the institution's involvement with academic assessment, (c) the proximity to the researcher's location, and (d) ease of access. The research focused on the possible factors involved in faculty engagement in the assessment of student learning. More specifically, it examined the results of a quantitative survey related to the perceptions of faculty member participants to inform the focus of the topics discussed in the campus-wide focus group. Institutional Review Board approval and informed consent of each survey and focus group participant were obtained.

IJERE Vol. 7, No. 3, September 2018: $167-175$ 


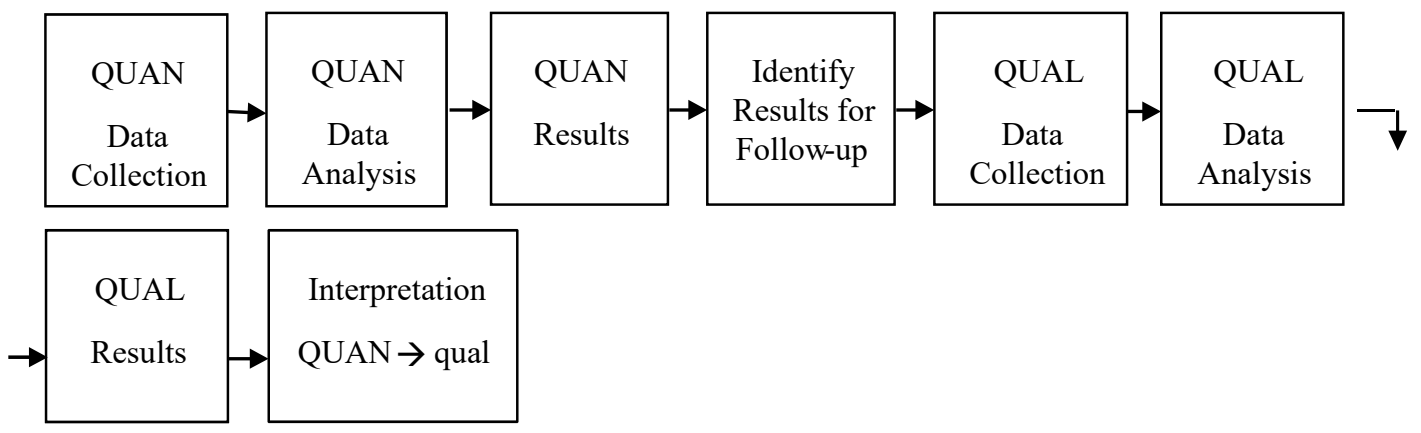

Figure 1. Explanatory Sequential Design: Follow-up Explanations Model (QUAN emphasized) [19: p. 73].

\subsection{Quantitative Method}

The survey was administered to identify the factors that influence faculty members' engagement in assessment. This survey was hosted on the case institution's basic subscription SurveyMonkey and consists of 108 items that examine the faculty members' perceptions of the value and use of assessment, their perceived barriers and challenges, and their concerns related to engaging in assessment activities. This survey was designed to take no more than 15 minutes to complete. Results from this survey were analyzed for the purposes of aggregating them for use in the focus group, which engaged in discourse about how to foster a culture of assessment and to inform policy related to assessment at the case institution.

Making use of 45 items from an existing survey about faculty members' attitude towards assessment [15], a 108-item survey instrument was developed to examine faculty perceptions of their value of assessment, their perceived barriers and challenges, their concerns related to engaging in assessment activities, their knowledge and experience in assessment, as well as the availability of necessary resources. All opinion items used a four-point Likert scale, ranging from "strongly disagree" to "strongly agree," or from "not apply at all" to "apply to great extent." The survey was administered in April 2014. All 146 faculty members were invited via email to participate in the online survey for a two-week period of the 146 invited faculty members, 36 had participated and 33 had completed all survey items with valid responses.

Because the sample size was inadequate for conducting a multivariate analysis as was planned originally, multiple regression was used to determine the relationships among the two criterion variables of willingness to engage in assessment and engagement in assessment, along with the eight predictor variables of: (a) lack of knowledge; (b) lack of support and resources; (c) concern of assessment as a threatening to faculty's autonomy; (d) assessment as a time consuming activity; (e) assessment is useful for the improvement of teaching; (f) assessment for faculty evaluation; (g) assessment as scholarly work; and (h) the culture of assessment at the institution.

\subsection{Qualitative Method}

A qualitative design enables researchers to obtain data directly from each participant that has knowledge and experience with the research topic [14]. In this study, we collected responses from focus group participants who had initial thoughts about the word, assessment, have been involved with assessment, have used assessment data to improve the courses they teach, have had conversations with others about assessment, and have some familiarity with the institutional policies and procedures related to assessment.

Informed by the findings from the survey results, a focus group was formed in March 2015 . The focus group consisted of 10 faculty members and both researchers. The focus group participants were selfselected through their response to an e-mail invitation requesting their participation. To provide a representative sample of the faculty population, selection for the focus group was based on the following factors: (a) gender; (b) race and ethnicity; (c) teaching discipline; (d) current status at the university (tenured, tenure-track, or adjunct/resource); (e) administrative role at the university and (f) years of college teaching experience.

\section{RESULTS AND ANALYSIS}

The case study institution had 156 full-time and 205 part-time faculty members. The number of faculty members and demographic breakdown are shown in Table 1. 
Table 1. Faculty Sample Population Demographics

\begin{tabular}{ccc}
\hline Category & Number of Participants (n) & Percentage of Campus Population \\
\hline Male & 6 & 50.6 \\
Female & 4 & 49.6 \\
Asian & 1 & 3.2 \\
Caucasian & 6 & 59.6 \\
Other & 3 & 9.0 \\
Tenure Track/Tenured & 10 & 75.6 \\
Total Sample & 10 & 6.4 percent of total population \\
\hline
\end{tabular}

Note: There were no full-time faculty members that identified the races not shown in this table.

Quantitative Findings: Survey Responses.

There were 37 faculty members who responded the online survey, with 33 valid responses. The valid response rate was $22.6 \%$. Prior to running statistical analyses, the reliability and validity of the survey instrument were tested. Factor analysis was conducted and some items were dropped to increase consistency among items for one factor. Factor analysis was conducted again with the revised survey instrument. Table 2 contains the summary of the results of factor analysis after dropping inconsistent items. All values of Cronbach's Alpha were above 0.7 , which can be considered good for internal consistency reliability. Using the cleaned data, a descriptive data analysis was conducted and the results are summarized in Table 3.

Table 2. Reliability Analysis of the Survey Response Data

\begin{tabular}{ccc}
\hline Variables & Items & Cronbach's Alpha \\
\hline Participation in Assessment & 6 & 0.887 \\
Willingness & 4 & 0.874 \\
Lack of Knowledge & 3 & 0.906 \\
Lack of Support & 4 & 0.807 \\
Concern of Threatening & 3 & 0.791 \\
Time Consuming & 3 & 0.936 \\
Assessment for Improvement & 6 & 0.874 \\
Assessment as Faculty Evaluation & 3 & 0.914 \\
As Scholarly Work & 4 & 0.750 \\
Institutional Culture of Assessment & 4 & 0.871 \\
\hline
\end{tabular}

Table 3. Descriptive Analysis of Variable Data

\begin{tabular}{ccc}
\hline Variables & Mean & Standard Deviation \\
\hline Willingness & 1.9597 & .9176 \\
Participation & 2.1613 & .7811 \\
Scholarly Work & 2.5417 & .4157 \\
Time on Assessment & 1.5054 & .8383 \\
Improve Teaching & 2.5538 & .4180 \\
As Evaluation & 1.6774 & .8839 \\
Lack of Knowledge & 1.1613 & .9808 \\
Lack of Support & 1.2473 & .9025 \\
Culture of Assessment & 2.0323 & .7739 \\
\hline
\end{tabular}

To find out which factor influences willingness and actual participation in assessment, linear regression analyses were conducted. The results indicating participants' belief that assessment can improve quality of teaching is the single significant factor to predict a faculty member's willingness to engage in assessment. There was no single factor to predict significantly the actual participation in assessment activities, as shown in Table 4.

Table 4. Analysis of Faculty Members' Willingness to Engage in Assessment Variables

\begin{tabular}{cccc}
\hline Variables & B & SE & Beta \\
\hline Scholarly Work & 1.441 & .296 & .065 \\
Time on Assessment & -.200 & .159 & -.186 \\
Improve Teaching & 1.500 & .287 & $.685^{* * *}$ \\
As Evaluation & -.039 & .128 & -.037 \\
Lack of Knowledge & .173 & .113 & .184 \\
Lack of Support & .140 & .156 & .140 \\
Culture of Assessment & .286 & .167 & .243 \\
\hline
\end{tabular}

$* * * \mathrm{p}<.001$

Note: Pearson correlation analysis revealed a significant correlation between Willingness and Participation $(\mathrm{r}=.461, \mathrm{p}<.01)$.

IJERE Vol. 7, No. 3, September 2018: $167-175$ 
We also conducted a t-test to find out if there was a difference by gender, age, or years of teaching among the following variables: willingness, actual participation, and eight opinion variables. The t-test results indicate men are more likely to engage in assessment activities than are women $(\mathrm{t}=-2.158, \mathrm{p}<.05)$, but there was no difference in actual participation in assessment by gender nor were there any differences across all opinion variables. The results also suggest that neither age nor years of teaching was a factor to significantly influence willingness, actual participation, and all opinion variables.

The preliminary analysis of the survey data suggests a higher level of willingness and a higher level of actual participation in assessment activities. Individual faculty members' beliefs, attitudes towards assessment, and their assessment practices vary significantly (as shown by the large standard deviation of each variable) which suggest consensus had not been formed and assessment had not become a standardized practice at the institution. However, the results of the multiple regression analysis of all participants' responses suggest the belief in assessment as a way of improving teaching and learning as being the single most significant factor that affects faculty members' willingness and participation in assessment activities. This is supported by the conventional wisdom that faculty members' motives for action were driven by this core value of higher learning. Even though they perceived assessment as a time consuming activity, faculty members conducted assessment as though they believed it could improve teaching and learning. The findings also indicate the means of improving faculty members' efficacy and policies for promoting their engagement in assessment.

Some expected findings were not evident from the analysis of the survey data, such as faculty members' belief that assessment is scholarly work which promotes engagement in assessment. The small sample size (n) may have been the reason and thus, a larger sample size is needed for producing robust, generalizable results. Moreover, the findings from the quantitative analysis indicated the use of an explanatory sequential mixed method design would be more fitting to reveal more specifically and holistically the interactions between the independent and dependent variables being examined.

\subsection{Qualitative Findings: Online Focus Group Dialogues}

As a means for validating and expounding on the quantitative findings from the survey, open-ended survey item \#21 and the focus group discussion forums were included in the analysis. Analysis of the responses revealed five qualitative themes (in the horizontal axis) and sub-themes identified and summarized in Table 5. All 295 valid responses were reviewed, coded, and counted after removing those that were not meaningful to the study. Also included were those responses to survey item 21 as a means of qualitatively informing the focus group responses making "the task of determining the themes and sub-themes less problematic. For example, item 21 pertained to reaction to assessment and familiarization with assessment policies and procedures; two of the identified themes shown in Table 6.

Table 5. Qualitative Themes and Sub-Themes from Focus Group Forums

\begin{tabular}{|c|c|c|c|c|c|c|}
\hline \multicolumn{7}{|c|}{ Qualitative Themes } \\
\hline $\begin{array}{l}\text { Sub- } \\
\text { Themes }\end{array}$ & $\mathrm{N}$ & $\begin{array}{l}\text { Reaction to (\%) } \\
\text { Assessment }\end{array}$ & $\begin{array}{l}\text { Involvement in } \\
(\%) \text { Assessment }\end{array}$ & $\begin{array}{l}\text { Use of Data for } \\
(\%) \text { Improvement }\end{array}$ & $\begin{array}{l}\text { Dialogues about } \\
(\%) \text { Assessment }\end{array}$ & $\begin{array}{l}\text { Familiarization with }(\%) \\
\text { Policies \& Procedures }\end{array}$ \\
\hline Importance & (21) & \begin{tabular}{l}
\multicolumn{1}{c}{4.7} \\
"The first thing \\
that comes to \\
mind when I \\
think about \\
assessment is [it \\
is] necessary." \\
to improve the
\end{tabular} & $\begin{array}{l}.3 \\
\text { "I quite like the } \\
\text { subject and have } \\
\text { learned about } \\
\text { myself and my } \\
\text { students: how they } \\
\text { learn..." the } \\
\text { assessment }\end{array}$ & $\begin{array}{l}.7 \\
\text { "The critical part } \\
\text { of the assessment } \\
\text { is how to generate } \\
\text { the meaningful ..." } \\
\text { data and use the } \\
\text { results } \\
\text { performance..." }\end{array}$ & $\begin{array}{l}1.4 \\
\text { "...conversations } \\
\text { that look across } \\
\text { the board at COB } \\
\text { and MBA } \\
\text { assessments as } \\
\text { part of the } \\
\text { assessment } \\
\text { committee } \\
\text { process..." }\end{array}$ & - \\
\hline Engaging & (94) & $\begin{array}{l}\quad 6.1 \\
\text { "I have been } \\
\text { very } \\
\text { comfortable } \\
\text { with assessing } \\
\text { all of my } \\
\text { courses this } \\
\text { past two years." }\end{array}$ & $\begin{array}{l}16.3 \\
\text { "I am continually } \\
\text { reviewing the } \\
\text { methods and } \\
\text { instruments used } \\
\text { in my classes to } \\
\text { try and help } \\
\text { students improve } \\
\text { their } \\
\text { performance." }\end{array}$ & $\begin{array}{c}3.4 \\
\text { "We've talked } \\
\text { about whether or } \\
\text { not our } \\
\text { assessments are } \\
\text { measuring what } \\
\text { we are trying to } \\
\text { measure..." }\end{array}$ & $\begin{array}{l}5.4 \\
\text { "Those } \\
\text { conversations } \\
\text { tend to be the } \\
\text { most productive } \\
\text { and } \\
\text { informative." }\end{array}$ & $\begin{array}{l}.7 \\
\text { Now that I'm on the } \\
\text { [college] assessment } \\
\text { committee, I'm learning } \\
\text { more about [policies \& } \\
\text { proc]" }\end{array}$ \\
\hline Planning & (36) & $\begin{array}{l}4.7 \\
\text { "I have come to } \\
\text { appreciate the } \\
\text { process of }\end{array}$ & $\begin{array}{c}5.8 \\
\text { "Coordinating } \\
\text { assessment } \\
\text { activities can } \\
\end{array}$ & $\begin{array}{c}.3 \\
\text { "Without careful } \\
\text { planning, } \\
\text { assessment can }\end{array}$ & $\begin{array}{l}1.0 \\
\text { "All of us have } \\
\text { met as a college } \\
\text { to discuss our }\end{array}$ & $\begin{array}{l}.3 \\
\text { "I also understand that } \\
\text { committees are being } \\
\text { reformed." }\end{array}$ \\
\hline
\end{tabular}

Understanding Faculty Engagement in Assessment through Feedback and Dialogues ... (Robert W. Elliott) 
Table 5. Qualitative Themes and Sub-Themes from Focus Group Forums

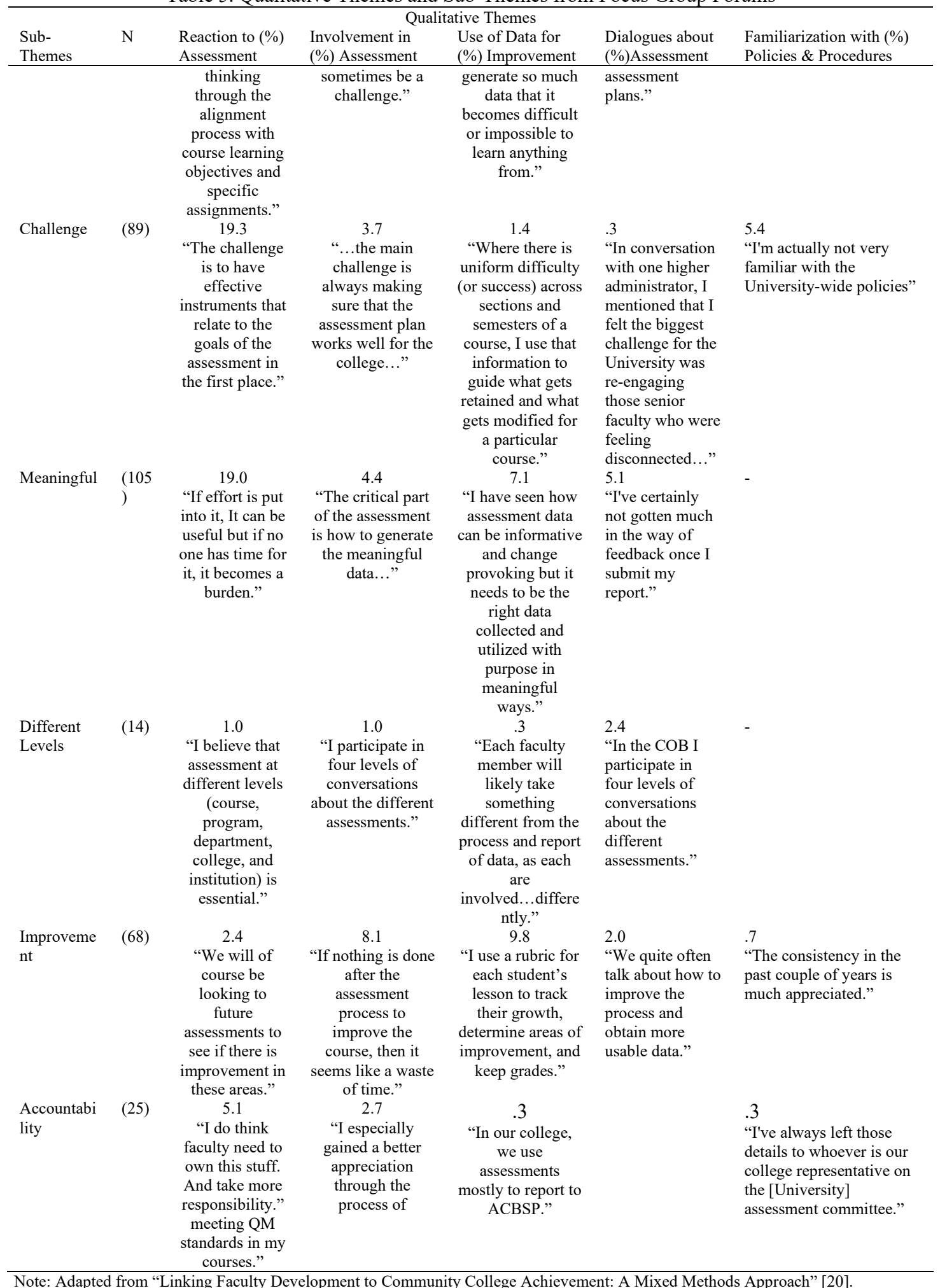

Note: Adapted from "Linking Faculty Development to Community College Achievement: A Mixed Methods Approach" [20]. 
Table 6. Matrix of Themes and Sub-Themes from Qualitative and Quantitative Components Overarching Themes

Certain factors
influence faculty
members'
perceptions,
attitudes, and
engagement in

assessment activities

$\begin{array}{cc}\begin{array}{c}\text { Various factors } \\ \text { affect faculty } \\ \text { members' }\end{array} & \begin{array}{c}\text { Knowledge of the } \\ \text { factors and how } \\ \text { they influence } \\ \text { perceptions, } \\ \text { faculty members } \\ \text { can be used to help }\end{array} \\ \text { engagement in } & \begin{array}{c}\text { define the culture } \\ \text { of assessment. }\end{array}\end{array}$

different ways of assessment.

Themes and Sub-Themes from Faculty Survey Responses (Quantitative)

1. Willingness to engage in assessment

2. Participation in assessment

3. Knowledge about assessment

4. Support for assessment

5. Concern of threatening environment

6. Time consuming

7. Assessment for improvement

8. Assessment as faculty evaluation

9. Assessment as scholarly work

10. Culture of assessment

Themes and Sub-Themes from Faculty Focus

Group and Constructed Survey Item \#21 Responses (Qualitative)

1. Faculty members expressed mixed reactions about

"assessment," but most perceived it as being essential

a. Necessity of some aspects varied

b. Viewed as resource intensive

c. Need for clear understanding of purpose evident

2. Faculty members perceived their involvement with assessment was tied to their role and opportunity

a. Increases in appreciation through engagement

b. Serving on committees increased appreciation

c. Viewed as a continuous learning process

3. Faculty members valued the use of assessment data to improve student learning, but perceived analyzing the data as being the most challenging and time consuming

a. Requires scarce resources and shifting priorities

b. Requires balance of quantity vs. quality of data

c. Making sense of the data for improvement

4. Faculty members have mixed experiences with dialogues about assessment

a. Some find much value while others are turned off by assessment

b. Shared discoveries through conversations

c. Topics of conversation included various aspects

5. Faculty members indicated their familiarization with assessment policies and procedures was dependent on their role and need

a. Mixed levels of familiarization depending on their time as a faculty

member and at the institution, as well as their experience with assessment

b. Dependent on the extent of their involvement

c. Serving on committees at various levels increases their familiarization

6. Faculty members indicated their attitude toward the focus group design was positive

a. The 10-day period was optimal

b. Viewed the experience as beneficial

$\cdot$

c. No "best" time to run the focus group but being early in the semester seemed to work out the best.

Note: Adapted from "Linking Faculty Development to Community College Achievement: A

Mixed Methods Approach" [20].

The "•" indicates a theme, and the "X" a sub-theme that intersects with each overarching theme.

\subsection{Integrating the Themes}

Based on the "prototypical follow-up explanations variant" mixed methods design that Creswell and

Plano Clark [19: para 1] describe, qualitative and quantitative methods were used to examine possible factors that can be used to define the culture of assessment among faculty members at the case institution. The mixed methods findings are then mixed together during analysis of both sets of data into one overall interpretation [19] by using the Matrix of Themes and Subthemes from Qualitative and Quantitative Components shown in Tables 5 \& 6 .

The literature indicates assessment of student learning outcomes at higher education institutions is an integrated part of teaching and an important way to improve student learning, and thus professional 
associations endorse and call for assessment in higher education institutions. Meanwhile, student learning outcomes assessment is also an important criterion for accreditation.

The findings from this study support the use of the Explanatory Sequential Design Model for analysis of the survey and interview data to reveal factors of faculty engagement in the assessment of student learning at the case institution. Furthermore, they reinforce Fishbein and Ajzen's [16] reasoned action and Bandura's [17] social cognitive theory as predictors of behavior among faculty members when it comes to assessment activities. The data analysis indicates factors that can be used as a possible means of defining the culture of assessment at the case institution. Table 6 shows the intersections of themes and subthemes found during the analysis of the qualitative and quantitative data sets; Table 5 facilitated the identification of these intersections. The overarching themes (in the horizontal axis) emerged from the synthesis of the results. In addition, the use of the Blackboard Learning Management System as a platform to conduct the focus group discussions was especially useful as it allowed faculty participants to express their thoughts and perceptions asynchronously at a time that was most convenient for them. Just as has been found with students engaged in online courses, faculty members expressed their satisfaction with having the freedom to express their thoughts about the focus group topics when they were ready and willing to do so within the two-week period.

\subsection{Other Considerations}

Limitations of the study included the lack of generalizability inherent in qualitative research, coupled with the low number of survey participants. For the quantitative portion of the study, limitations included the final sample population of faculty members $(n=33)$ not being randomly selected sample and the population $(\mathrm{N}=146)$ being relatively small. Voluntary completion of all, some, or none of survey items presents another limitation, as participants are given a choice of responding/not responding.

Of particular importance with regard to the low sample size, even if all faculty members had participated, the sample size is less than optimal to produce results that are very robust for making generalizations to other populations. For this reason, use of the mixed methods approach is worthwhile in the qualitative findings being used to explain the results of the quantitative analysis, as shown in Table 4.

\section{CONCLUSION}

A culture of assessment at many American higher education institutions is far from being fully established, and faculty engagement in assessment has been identified as the primary challenge for the task. Moreover, empirical studies that examine the factors that influence faculty engagement in assessment are few. This mixed methods study will contribute to the understanding of those factors and how they influence faculty members' willingness and engagement in assessment. This study also has implications for policymaking and professional development initiatives for promoting faculty members' engagement and fostering a culture of assessment in higher education institutions.

\section{ACKNOWLEDGEMENTS}

Much appreciation goes to my colleague, Dr. Jian Liu, for her persistence and involvement in seeing this study through to the end. Her inspiration gave me the motivation to keep going with the study of this topic to what is seen here in this published article.

\section{REFERENCES}

[1] Kuh, G. and Ikenberry, S. More than you think, less than we need: Learning outcomes assessment in American higher education. National Institute for Learning Outcomes Assessment. 2009; 1-36. Available from: http://www.learningoutcomeassessment.org/NILOAsurveyresults09.htm. [Accessed 14th July 2018].

[2] Fletcher, R.B., Meyer, L.H., Anderson, H., Johnston, P., Rees, M. Faculty and students conceptions of assessment in higher education. Higher Education. 2012; 64, 119-133. Springer.

[3] Banta, T. W. and Associates. Building a scholarship for assessment. San Francisco, CA: Jossey-Bass Publishers; 2002.

[4] Grunwald, H. \& Peterson, M.W. Factors that promote faculty involvement in and satisfaction with institutional and classroom student assessment. Research in Higher Education. 2003; 44(2), 173-204. Springer Sciences Press.

[5] Havnes, A. \& McDowell, L. Introduction: Assessment dilemmas in contemporary learning cultures. Book chapter in "Balancing Dilemmas in Assessment and Learning in Contemporary Education." Routledge Research in Education. 2008; 3-14. Routledge: New York.

[6] Maki, P. L. Building a sustainable commitment across the institution: Assessing for learning (2nd ed.). Sterling, VA: Stylus Publishing; 2010.

IJERE Vol. 7, No. 3, September 2018 : $167-175$ 
[7] Palomba, C. A. and Banta, T. W. Assessment essentials: Planning, implementing and improving assessment in higher education. San Francisco, CA: Jossey-Bass Publishers; 2015.

[8] Hutchings, P., Taylor Huber, M., Ciccone, A. The scholarship of teaching and learning reconsidered: Institutional integration and impact. Jossey-Bass: San Francisco. 2011.

[9] Elliott, R.W. Faculty development curriculum: What informs it? Journal of Faculty Development. 2014; 28(3), 4959. New Forums Press, Inc: Stillwater.

[10] Liu, L. Value-added assessment in higher education: A comparison of two methods. Higher Education. 2011; 61, 445-461. Springer.

[11] Welsh, J. F. \& Metcalf, J. Cultivating faculty support for institutional effectiveness activities: Benchmarking best practices. Assessment and Evaluation in Higher Education. 2003; 28(1), 33-45. Taylor and Francis Group.

[12] Andrade, M.S. Managing change-Engaging faculty in assessment opportunities. Innovative Higher Education. $2011 ; 36,217-233$. Springer.

[13] Haviland, D., Shin, S.H., and Turley, S. "Now I'm ready: The impact of a professional development initiative on faculty concerns with program assessment." Innovative Higher Education. 2010; 35, 261-275.

[14] Paton, V.O., Elliott, R.W., Barnard-Brak, L., Ryan, P.M. Vertical transfer success: Hispanic student perceptions of transfer and transition issues. Journal for College Orientation and Transfer. 2015; 22(2), 40-60.

[15] Wang, X. L. and Hurley, S. Assessment as a scholarly activity? Faculty perceptions of and willingness to engage in student learning assessment. The Journal of General Education. 2012; 61(1), 1-15.

[16] Fishbein, M. and Ajzen, I. Belief, attitude, intention and behavior: An introduction to theory and research. Reading, MA: Addison-Wesley; 1975.

[17] Bandura, A. Social foundations of thought and action. Englewood Cliffs, New Jersey: Prentice-Hall; 2015.

[18] Hughes, J.C. Supporting curriculum assessment and development: Implications for the faculty role and institutional support. New Directions for Teaching and Learning. 2007; 112, 107-110. Wiley Periodicals, Inc.

[19] Creswell, J. W., \& Plano Clark, V. L. Designing and conducting mixed methods research (2nd ed.). Thousand Oaks, CA: Sage; 2015.

[20] Elliott, R.W. and Oliver, D.E. Linking faculty development to community college student achievement: A mixed methods approach. Community College Journal of Research and Practice. 2016; 40(2), 85-99. Available from: doi:10.1080/10668926.2014.961590. [Accessed 14 ${ }^{\text {th }}$ July 2018].

\section{BIOGRAPHY OF AUTHOR}

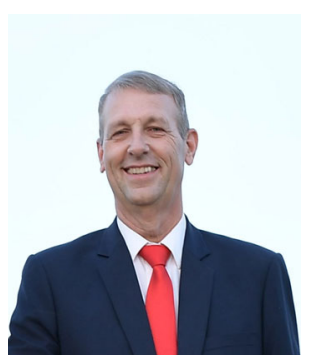

Robert Elliott is serving as Associate Professor in the Department of English, Foreign Language School, Linyi University at Linyi, Shandong, PRC. His research background includes postsecondary faculty development, student persistence, and the assessment of student learning in higher education. 